\title{
Evaluation of the Nursing Management for Patients on Underwater Chest Drainage at Kenyatta National Hospital
}

\author{
Anthony Chege ${ }^{1 *}$, James Mwaura², Angeline Kirui ${ }^{2}$ \\ ${ }^{1}$ Medical Surgical Nursing, School of Nursing Sciences; University of Nairobi, Nairobi, Kenya \\ ${ }^{2}$ School of Nursing Sciences, University of Nairobi, Nairobi, Kenya \\ Email: ^antkarazg@gmail.com, jmwaura@uonbi.ac.ke, angelinechepchirchir@gmail.com
}

How to cite this paper: Chege, A., Mwaura, J. and Kirui, A. (2018) Evaluation of the Nursing Management for Patients on Underwater Chest Drainage at Kenyatta National Hospital. Open Journal of Obstetrics and Gynecology, 8, 1222-1235.

https://doi.org/10.4236/ojog.2018.812124

Received: August 28, 2018

Accepted: October 23, 2018

Published: October 26, 2018

Copyright $\odot 2018$ by authors and Scientific Research Publishing Inc. This work is licensed under the Creative Commons Attribution International License (CC BY 4.0).

http://creativecommons.org/licenses/by/4.0/

(c) (i) Open Access

\begin{abstract}
Aim: To evaluate the nursing management for patients undergoing underwater chest drainage (UWCD) management at Kenyatta National hospital $(\mathrm{KNH})$. Methods: A cross-sectional study conducted at the medical and surgical wards of KNH. Data were obtained from 101 consenting nurses selected through simple random sampling using a researcher administered questionnaire. Ten participant observations were made among nurses who were systematically sampled. Ten key informant interviews were conducted among nurse managers of these departments who were purposively sampled. Data were analysed using SPSS version 21. Findings: Most participants (46.5\%) had average knowledge while $6.9 \%$ were poor. This means that $46.5 \%$ of the participants either had to refer to guidelines on UWCD management or assisted by a more competent nurse while $6.9 \%$ were unable to manage UWCD patients. Factors affecting the levels of knowledge and competence included level of nursing education $(\mathrm{p}=0.043)$, length of working experience $(\mathrm{p}=$ 0.022 ) and the attitude of the participants towards UWCD nursing management $(\mathrm{p}=0.022)$. There was low adherence to the Nursing Council of Kenya (NCK) guidelines (17\%). Most nurses used "shortcuts" in provision of care. Majority (62.6\%) faced challenges in provision of care. The challenges include inadequate knowledge (37.1\%), heavy workload (27.4\%) and lack of guidelines (16.9\%). Conclusions: There is a knowledge and competence gap in the nursing management of UWCD patients at KNH. Majority used "shortcuts" in nursing care with low adherence to NCK guidelines. There is a need to improve the knowledge and competence in order to ensure patients safety and reduce complications.
\end{abstract}

\section{Keywords}

Underwater Chest Drainage, Management, Knowledge, Adherence, 
Challenges

\section{Background}

Underwater chest drain is a safe and efficient procedure that is used to drain pleural collections including blood, air, pus and lymphatic fluid both in trauma and nontraumatic origins [1] [2] [3] [4]. Patient safety is promoted when the nurses are competent and their knowledge, skills, attitude and performance are related to evidence based practice protocols and standards of care [5] [6] [7] [8] [9].

Nurses at Kenyatta National Hospital have been increasingly faced with the burden of managing patients on underwater chest drainage treatment both complicated and uncomplicated. Over 500 UWCD patients are managed at $\mathrm{KNH}$ annually. This is partly due to the increase in chest trauma secondary to gunshot injuries and road traffic accidents which account for $61 \%$ of pre-hospital trauma related deaths in Nairobi [10] [11] [12]. Partly also due to the high prevalence of HIV related pleural effusion in most regions within the country [13].

Studies done have shown that the nursing management of chest tubes requires more specific orientation of nurses on the care and maintenance. Over $75 \%$ of nurses are competent in the general management of chest tubes while only $41 \%$ are competent in the management of clogged chest tubes, which is a common complication [14] [15].

At $\mathrm{KNH}$ most nurses report lack of adequate knowledge and proper orientation in the management of underwater chest drainage systems. Some of the chest drains remain clogged and unnoticed by the nurses while others dislodge without prompt detection and intervention. There is prolonged hospitalization of patients with chest drains at $\mathrm{KNH}$ [16] [17].

Most nurses at $\mathrm{KNH}$ were observed to use varied practice during provision of care to underwater chest drainage patients. This therefore raises the concern on the adherence to standard nursing guidelines in the provision of care to patients on under water chest drainage system at $\mathrm{KNH}$.

There is no research conducted regarding the nursing management of underwater chest drains in Kenya and therefore reducing the concern on the need to improve the nursing management of underwater chest drains and further relegating the role of nurses to passive management. There is need therefore to provide evidence based practice on the nursing management of underwater chest drainage.

\section{Materials and Methods}

\subsection{Study Design and Setting}

A cross sectional study carried out within medical and surgical wards between April and June 2017 at Kenyatta National Hospital, in Nairobi, Kenya. This is a 
National Referral Hospital with a bed capacity of 2000. It offers both preventative and curative services for a variety of illnesses to patients from all over Kenya with an average of 600,000 outpatient visits and 89,000 inpatients annually. Pretesting of the study instruments was done at Kiambu level IV hospital that is a public referral hospital within Kiambu County neighbouring Nairobi County. The research participants for the questionnaires and participant observations consisted of the primary nurses directly involved in provision of nursing care to underwater chest drainage patients. The key informant interviews were conducted among the nurse managers heading the departments where underwater chest drainage patients were admitted and managed. The data collected captured both qualitative and quantitative aspects of underwater chest drainage nursing management.

\subsection{Sampling Technique}

Simple random sampling method was used to select the study sample for the researcher-administered questionnaires. Folded papers written 1 to 101 were put in the basket whereas 284 blank folded papers were put in the same basket. Nurses were randomly allowed to pick the papers after consenting to participate in the study. Those who picked a random number participated while those who picked a blank did not. Study participants for the participant observation were systematically sampled whereby the first one was randomly sampled, every fourth participant who was found providing nursing care to patients on UWCD participated in the study upon consent. Key informants were purposively sampled from the ward managers in charge of the medical and surgical wards where UWCD patients are managed.

\subsection{Collection and Data Quality Control}

A questionnaire was developed by the researcher and pretested for reliability and validity at Kiambu level IV hospital. The reliability value was 0.82 answering the same latent variable as the overall question in the likert scale. The validity was higher than 0.6. The pretested researcher administered questionnaire was used to collect information on the participants' demographic characteristics, attitude towards nursing management of UWCD and participation in continuous medical education.

Knowledge on UWCD nursing management was determined, the level of adherence to the Nursing Council of Kenya guidelines and the challenges faced in the nursing management of underwater chest drains were evaluated. The observation check lists and the key informant interviews were also used to collect both qualitative and quantitative data.

The study instruments were pre-tested with $10 \%$ of the study's sample size in Kiambu level IV hospital. It is a public hospital like $\mathrm{KNH}$ and serves a population with similar characteristics to those in $\mathrm{KNH}$. One research assistant who was a registered Bsc nurse was trained on data collection process. Moreover, the principal investigator was monitoring the data collection on daily basis. 


\subsection{Data Analysis}

Data collected was entered into a Microsoft excel spread sheet and analysed using Statistical Package for Social Sciences (SPSS) version 21.0 (IBM Corporation, Armonk, NY, USA). Pearson's chi-square test was used to establish the association between the dependent variable and independent variables in order to determine which ones had significant association. Multinomial logistic regression was used to model Knowledge of nurses in the management of UWCD patients using factors identified to be significant at $\mathrm{P}<0.05$. Qualitative data was transcribed, translated and analyzed manually.

\subsection{Ethical Permissions}

Study approval was sought from the Kenyatta National Hospital/university of Nairobi Ethics and Research committee (KNH/UON-ERC). A written informed consent was sought from all study participants after they were given participant information, before they were interviewed. Participation was purely on voluntary basis. Privacy and confidentiality were maintained while handling participants' information.

\section{Findings}

\subsection{Response Rate}

The response rate for the study was $100 \%$ during data collection. The high response rate was attributed to perception of the participants on the importance of research and evidence based practice.

\subsection{Demographic Characteristics}

A total number of 101 nurses participated in the study. Majority (51.5\%) of the respondents were aged between 31 - 40 years with $2 \%$ above 51 years. There were more female respondents (56.4\%). Majority (59.6\%) had attained a diploma in nursing as their highest level of professional training. Only $2 \%$ of the respondents had acquired a master's degree in nursing. Majority (52.5\%) of the respondents were deployed/working in the surgical wards with a working experience of between 6 - 10 years (31.7\%).

\subsection{Nurses Attitude towards UWCD Management}

Majority (84\%) of the respondents perceived the role of nurses in the management of UWCD patients as important and, only $15 \%$ and $1 \%$ of respondents indicated that nurses have a minimal role and no role respectively. Participants who perceived the role of nurses in UWCD management as important were more likely to be knowledgeable than those who perceived nurses had a minimal role and no role respectively $\left(\chi^{2}=12.413 ; \mathrm{df}=6 ; \mathrm{p}=0.043\right)$. The finding was similar in the key informant interviews, whereby "Motivation and attitude" were cited as factors that influenced the knowledge and competence among the indi- 
vidual nurses in UWCD management.

\subsection{Participation in Continuous Medical Education}

Of the respondents, $54.5 \%$ reported to have attended continuous medical education (CME) on UWCD management. Participation in CMEs is not likely influence the level of competence in UWCD nursing management $\left(\chi^{2}=1.478 ; \mathrm{df}=2\right.$; $\mathrm{p}=0.478$ ). The key informants however stated that "frequent updates" in the form of CMEs improved the knowledge and competence among nurses.

\subsection{Nurses Knowledge in the Management of UWCD}

Of the respondents, $46.5 \%$ had average knowledge in UWCD nursing management. $6.9 \%$ had poor levels of knowledge. Participants with very good knowledge were knowledgeable, competent in management of UWCD and capable of instructing their colleagues, those rated as good were knowledgeable and competent but not capable of instructing colleagues, Average participants were not adequately knowledgeable and competent without referring to the guidelines whereas poor did not feel knowledgeable and competent even with the use of guidelines. Participants who had a higher level of training had more knowledge in UWCD management $\left(\chi^{2}=13.01 ; \mathrm{df}=3 ; \mathrm{p}=0.043\right)$ (Table 1$)$. Those who perceived the nurses' knowledge in UWCD as important were more likely to be

Table 1. Relationship between socio-demographic characteristics and the knowledge in UWCD nursing management.

\begin{tabular}{|c|c|c|c|c|c|}
\hline \multicolumn{2}{|c|}{ Characteristics } & Frequency $[n,(\%)]$ & $\chi^{2}$ & $\mathrm{df}$ & $\mathbf{P}$ \\
\hline \multirow{3}{*}{ Age } & 21 - 30 years & $31(30.7 \%)$ & & & \\
\hline & $31-40$ years & $52(51.5 \%)$ & & & \\
\hline & 41 - 50 years & $16(15.8 \%)$ & 4.562 & 6 & 0.601 \\
\hline \multirow{3}{*}{ Gender } & Above 51 years & $2(2 \%)$ & & & \\
\hline & Male & $44(43.6 \%)$ & 0.795 & 2 & 0.672 \\
\hline & Female & $57(56.4 \%)$ & & & \\
\hline \multirow{4}{*}{ Level of training } & Certificate (KECHN) & $10(9.6 \%)$ & & & \\
\hline & Diploma (KRCHN) & $62(59.6 \%)$ & 13.005 & 6 & $0.043^{*}$ \\
\hline & Bachelor's degree (BscN) & $30(28.8 \%)$ & & & \\
\hline & Master's degree $(\mathrm{MscN})$ & $2(1.9 \%)$ & & & \\
\hline \multirow{2}{*}{ Department } & Surgery & $53(52.5 \%)$ & & & \\
\hline & Medicine & $48(47.5 \%)$ & 3.969 & 2 & 0.137 \\
\hline \multirow{5}{*}{ Length of experience } & $0-5$ years & $27(26.7 \%)$ & & & \\
\hline & $6-10$ years & $32(31.7 \%)$ & & & \\
\hline & $11-15$ years & $27(26.7 \%)$ & 7.677 & 2 & $0.022^{*}$ \\
\hline & 16 - 20 years & $7(6.9 \%)$ & & & \\
\hline & Above 20 years & $8(7.9 \%)$ & & & \\
\hline
\end{tabular}

$\chi^{2}=$ Chi square; $\mathrm{df}=$ degree of freedom; ${ }^{\star}$ Significant at $\mathrm{p}<0.05$ (bolded). 
more competent in UWCD management $\left(\chi^{2}=12.413\right.$; $\left.\mathrm{df}=6 ; \mathrm{p}=0.043\right)$. Working experience was likely to influence knowledge and competence in UWCD management $\left(\chi^{2}=7.677 ; \mathrm{df}=2 ; \mathrm{p}=0.022\right)$. However, deployment of the respondents to either surgical or medical wards did not influence their level of knowledge/competence $\left(\chi^{2}=3.969 ; \mathrm{df}=2 ; \mathrm{p}=0.137\right)$.

\subsection{UWCD Management Using the Nursing Process}

The respondents' level of knowledge/competence in application of the nursing process in the management of UWCD patients was evaluated. A systematic approach was utilized in determining the level of competence in all the steps of the nursing process. Additionally, the respondents' knowledge in identifying the possible complications in UWCD patients was evaluated (Table 2).

Of the respondents $45.7 \%$, had average knowledge in nursing assessment while $3.6 \%$ were poor. $46.0 \%$ had average knowledge in nursing diagnosis while $7.1 \%$ were poor. $48.4 \%$ of the respondents perceived their level of competence in nursing implementation of interventions as average while $7.4 \%$ were poor. Nursing evaluation of UWCD was rated among 50\% as average and $8.2 \%$ were poor. $42.9 \%$ rated their ability in identifying the possible complications in UWCD patients as good and $6.7 \%$ were poor.

This implies that while utilizing the nursing process in the management of UWCD patients, most nurses require referring to the guidelines and or assistance by a more competent colleague to bridge their competence gap (Table 3 ).

\subsection{Nursing Documentation of UWCD}

Of the three observed practices in nursing documentation, the majority adhere to them. $100 \%$ of the participants were observed to document chest tube drainage, amount and color. In addition, 50\% recorded for complications, disconnections and dislodgements. $70 \%$ noted and documented the patient's condition.

\subsection{Complications in UWCD}

Lung infections (32.9\%) was identified as the major complication encountered by nurses in UWCD management, other complications mentioned were pneumothorax (17.7\%), Bleeding (13.5\%), Pleural effusion (8.4\%) and Septicaemia $(6.3 \%)$.

\subsection{Adherence to Nursing Guidelines in UWCD Management}

Majority (83\%) of the respondents were not aware of any guidelines in UWCD nursing management. Of the respondents who were aware of the guidelines in UWCD management, the majority (75\%) stated that they obtained guidelines from internet sources. For the respondents unaware of standard guidelines in UWCD care, principles they use to guide their provision of care include information from basic nursing training (62.5\%) and through work experience (18.8\%). 
Table 2. Observed practices in nursing assessment of patients on UWCD.

\begin{tabular}{lcccc}
\hline \multirow{2}{*}{$\begin{array}{l}\text { Observed practices in nursing assessment of patients on UWCD } \\
\text { Score (\%) }\end{array}$} & Nes & No \\
\cline { 2 - 4 } Assessment of the patients respiratory status by auscultation & 10 & 90 & 10 \\
Assessment that the chest tube is set to appropriate suction & 20 & 80 & 10 \\
$\begin{array}{l}\text { Assessment whether the water level in the water seal chamber is maintained at } \\
\text { the marked line }\end{array}$ & 60 & 40 & 10 \\
Assessment for air leaks in the water seal chamber & 10 & 90 & 10 \\
Assessment if the chest tube connections and dressings are secure & 100 & 0 & 10 \\
Assessment of the drainage system for the color and the amount of drainage & 90 & 10 & 10 \\
Assessment for the level of pain & 70 & 30 & 10 \\
Assessment of the patency of the tubing system & 70 & 30 & 10 \\
\hline
\end{tabular}

Table 3. Observed practices on the nursing implementation of care to UWCD patients.

\begin{tabular}{|c|c|c|c|}
\hline \multirow{2}{*}{$\begin{array}{l}\text { Observed practices in nursing implementation of care to patients on } \\
\text { UWCD }\end{array}$} & \multicolumn{2}{|c|}{ Score $(\%)$} & \multirow{2}{*}{$\mathbf{N}$} \\
\hline & Yes & No & \\
\hline Setting the suction pressure to $20 \mathrm{~cm}$ of water & 10.0 & 90.0 & 10 \\
\hline Change of dressing every $24-48 \mathrm{hrs}$ & 80.0 & 20.0 & 10 \\
\hline Ensure that occlusive dressing is applied on the chest tube & 90.0 & 10.0 & 10 \\
\hline Ensure the chest tube is not milked or stripped to maintain patency & 80.0 & 20.0 & 10 \\
\hline Ensure that the drain is lower than the level of the patient & 100.0 & 0.0 & 10 \\
\hline $\begin{array}{l}\text { Ensure that the tubing is free from kinks and dependent loops and is not } \\
\text { pinned to the bed linen }\end{array}$ & 50.0 & 50.0 & 10 \\
\hline Connects the tubing to the chamber and the patient & 90.0 & 10.0 & 10 \\
\hline
\end{tabular}

The key informant interviews also revealed a low adherence to guidelines among nurses in provision of care, "Nurses mostly use shortcuts in providing care to patients on UWCDs, sometimes without the use of trolleys".

The reasons cited by the respondents for non-adherence of the nursing guidelines include; unawareness of the guidelines (37.1\%), heavy workload $27.4 \%$. $0.8 \%$ of the respondents said that "lack of cooperation from patient" was a reason hindering their adherence (Table 4).

\subsection{Challenges Encountered in the Nursing Management of UWCD}

Majority (62.6\%) indicated that they encountered challenges during provision of nursing care to UWCD patients. Of the respondents $23.2 \%$ encounter challenges related to the heavy workload, $13.1 \%$ cited inadequate knowledge as an impediment in provision of care among others. This was replicated in the key informant interviews whereby "work fatigue" was highlighted as among the challenges as well as "ignorance in underwater seal care".

\section{Discussion}

The study demonstrated an existing gap in the knowledge and competence of 
Table 4. Reasons why nurses do not adhere to guidelines in UWCD management.

\begin{tabular}{ccc}
\hline Reasons & Frequency & Percentage \\
\hline Unawareness of the guidelines & 46 & 37.1 \\
Heavy workload & 34 & 27.4 \\
Lack of guidelines in the working institutions & 21 & 16.9 \\
Inadequate training on the guidelines & 10 & 8.1 \\
Poor attitude and motivation & 4 & 3.2 \\
Inadequate resources for implementing the guidelines & 3 & 2.4 \\
Poor supervision & 3 & 2.4 \\
Lack of current updates & 2 & 1.6 \\
Lack of cooperation from patients & 1 & 0.8 \\
Total & 124 & 100 \\
\hline
\end{tabular}

nurses in the management of UWCD. $46.5 \%$ of the nurses could not competently provide care for underwater chest drains without either referring to guidelines or assisted by a more competent colleague. Participants with a higher level of nursing training had relatively higher levels of competence than those with lower levels of training $\left(\chi^{2}=13.01 ; \mathrm{df}=3 ; \mathrm{p}=0.043\right)$.

The level of knowledge in nursing assessment was mostly average among $45.7 \%$ of the respondents. $3.6 \%$ had poor knowledge in nursing assessment. The common assessment features among the participants included pain (23.4\%), respiratory rate (18.9\%), vital signs (12.6\%), wound assessment $(6.8 \%)$ and the drainage amount and color (5.4\%) (Table 2). However, a glaring majority of the observed participants (90\%) did not assess the patients' respiratory status by auscultation; they did not have a stethoscope as part of their preparation in patient assessment. Likewise, $80 \%$ did not assess whether the chest tube is set to the appropriate suction and only $10 \%$ assessed for air leakage in the chamber. The assessment was inadequate in evaluating the respiratory system and identifying the possible complications related to UWCD that can easily cause death among the patients (Table 2).

There was low utilization of nursing diagnosis in the patient management. $80 \%$ of the participants did not formulate appropriate nursing diagnosis to guide care. Common diagnostic labels among the participants who formulated nursing diagnosis include pain (23.6\%), risk for infection $17.9 \%$, anxiety $10.1 \%$, impaired tissue integrity $9.2 \%$. Some participants (18.4\%) used non-nursing diagnostic labels to include pneumothorax.

Most participants (48.4\%) are average in the knowledge and competence during implementation of care to UWCD patients. Common nursing interventions include administering analgesics (26.1\%), Monitor drainage (11.3\%), ensure hygiene and wound care (10.8\%), educating patients (9.5\%) and Patient positioning $(8.6 \%)$. The participants had poor knowledge regarding suction pressure in UWCD and $80 \%$ did not understand suction pressure. Milking and stripping of 
chest tubes was still a practice among $20 \%$ of the participants. There was poor understanding on whether or not to milk or strip chest tubes among the participants. $50 \%$ of the participants were observed to pin/secure the tubing to the bed linen with the use of forceps and strapping. This is a major cause of chest tube dislodging as a complication (Table 3).

Evaluation of UWCD patients was average among $50 \%$ of the participants while $8.2 \%$ were poor. Commonly evaluated features include pain control (22.2\%), respiratory rate (19.4\%), presence of infections (18.9\%), amount of drainage and color $(9.4 \%)$. There was good understanding on the evaluation of pain and relatively adequate pain control measures. However, focused respiratory system evaluation was poor with a majority (90\%) having poor understanding and did not therefore evaluate for an increase in pneumothorax. Only 3.9\% of the participants monitored the patients' oxygen saturation. It is therefore evident that nurses' mainstay evaluation in patients was UWCD was mainly on pain control. There was however, a relatively low concern on the patients respiratory functioning among the participants that is the ideal priority concern in such patients.

The participants mainly documented the color and amount of drainage (100\%). There was however no documentation of complications in $50 \%$ of the participants. In cases where the complications develop in UWCD, there was delayed reporting, poor communication therefore leading to late, and no interventions at all.

Majority of the respondents (83\%) were not aware of any nursing guidelines in the management of underwater chest drainage patients. This is attributable to the varied practices and standards of care among nurses in UWCD management. Of the respondents aware of nursing guidelines in UWCD management, the majority (75\%) stated that they followed guidelines from internet sources. This demonstrates the increased use of internet based information sources to guide nursing practice.

A majority (62.6\%) of the respondents faced challenges in provision of care to UWCD patients. The challenges were related to, heavy workload (23.2\%), poor knowledge (13.1\%), lack of equipment and supplies (11.6\%), incorrect insertion of the chest tubes (10.1\%), lack of clear guidelines (10.1\%), teamwork among others (Table 4).

The attitude of nurses on the perceived importance of nursing management in UWCD affects the nurses' knowledge and competence. $49 \%$ of nurses perceived the role of nurses in the management of UWCD as important while $15 \%$ felt that the role of nurses as minimal while $1 \%$ was no role respectively. A poor attitude potentially reduced nursing interventions to a passive role limited to nursing observations in UWCD patients.

\section{Conclusions}

The study demonstrated an existing gap in the knowledge and competence of nurses in the management of UWCD. Nursing practice in the care of UWCDs is 
varied with low adherence to the standard guidelines.

The study therefore recommends the need to provide clinical teaching and continuous medical education to nurses on UWCD management in order to improve competence and promote patient safety.

The hospital should develop a checklist to guide nursing care for patients on UWCD. This will help to improve the quality and standardization of care.

\section{Limitations of the Study}

1) Data collection process since some participants feared victimisation by the study.

2) Financial limitations.

\section{Acknowledgements}

The authors acknowledge all the nurses who participated in the study for their time and willingness. The authors also wish to give special thanks to the Kenyatta National administration for their cooperation and for granting the approval to conduct the study.

\section{Authors' Contributions}

Anthony Chege carried out the research project conception, data collection and writing the research project under the supervision of Dr James Mwaura and Mrs Angeline Kirui of the School of Nursing Sciences, University of Nairobi.

\section{Funding}

This research was self-funded.

\section{Conflicts of Interest}

The authors declare that they have no competing interests.

\section{References}

[1] George, R.S. and Papagiannopolous, K. (2016) Advances in Chest Drain Management in Thoracic Disease. Journal of Thoracic Disease, 8, S55-S64.

[2] Dewit, S. and Candice, K. (2013) Medical Surgical Nursing Concepts \& Practice. 2nd Edition, Saunders, Philadelphia.

[3] Edaigbini, S.A., Deila, I.Z. and Orogwe, A. (2014) Indications and Complications of Tube Thoracostomy with Improvised Underwater Seal Bottles. Nigerian Journal of Surgery, 20, 79-82. https://doi.org/10.4103/1117-6806.137305

[4] Kesieme, E.B., Dongo, A. and Ezemba, N. (2012) Tube Thoracostomy: Complications and Its Management. Pulmonary Medicine, 2012, Article ID: 256878. https://doi.org/10.1155/2012/256878

[5] Durai, R., Hoque, H. and Davies, T. (2010) Managing a Chest Tube and Drainage System. Http://www.ncbi.nlm.nih.gov/pubmed/20152201 https://doi.org/10.1016/j.aorn.2009.09.026

[6] Anne, H. (2010) Survey on the Major Complications of Intercostals Chest Drain 
Insertion in the UK. Post Graduate Medical Journal, 86, 68-72.

http://eropository.uonbi.ac.ke/bitstream/handle/11295/24643/omar/ https://doi.org/10.1136/pgmj.2009.087759

[7] Hyun, M.C., Yoon, J.H. and Chunsung, B. (2016) The Usefulness of a WI-FI Based Digital Chest Drainage System in the Post-Operative Care of Pneumothorax. Journal of Thoracic Disease, 8.

[8] Kesieme, E.B., Ifeanyichukwu, S.U. and Brono, J. (2016) The Knowledge of Care of Chest Drain: A Survey in Nigerian Semiurban University Hospital. Annals of African Medicine, 15. https://doi.org/10.4103/1596-3519.172556

[9] Fisseha, H., Ferehare, A. and Fikadu, B. (2014) Application of Nursing Process and Its Affecting Factors among Nurses Working in Mekelle Zone Hospitals North Ethiopia. Nursing Research and Practice, 2014, Article ID: 675212.

[10] Saidi, H. and Oduor, J. (2013) Trauma Deaths outside the Hospital: Uncovering the Typology in Kenya Capital. Journal of Forensic and Legal Medicine, 20, 570-574. https://doi.org/10.1016/j.jflm.2013.04.016

[11] Mohammed, M.H. (2015) Indications of Chest Tube Insertion Egyptian. Journal of Chest Diseases and Tuberculosis, 64.

[12] Obieze, C., Nwanna, N. and Ajiko, M.M. (2016) Barriers and Facilitators of Surgical Care in Rural Uganda. Journal of Surgical Research, 204, 242-250. https://doi.org/10.1016/j.jss.2016.04.051

[13] Oyaro, P.O., Penner, J. and Oyanga, A. (2015) WHO Stage IV Conditions among Adults in Kisumu Kenya. http://www.ncbi.nlm.nih.gov/pcm/articles/pmc/3939608/

[14] Cook, M. (2016) Nurses Perceptions of Chest Tube Care. Https://consultqd.clevelandclinic.org/2016/02/cns-research-nurses-comfort-chestube-mgt

[15] Mukhtar, O. (2005) The Management of Traumatic Haemothorax and Pneumothorax by Closed Tube Thoracostomy as Practiced in Kenyatta National Hospital.

[16] Mirlashi, J., Qommi, R. and Nariman, S. (2016) Competence of Nurses in Neonatal Intensive Care Unit. Journal of Caring Sciences, 2016.

[17] Jassim, S., Sabah, A.A. and Hussein, A. (2015) Evaluation of the Nursing Management for Patients Undergoing Water Seal Chest Tube Drainage System. Kufa Journal for Nursing Sciences, 5, 1-2. 


\section{Appendix}

\section{Study Questionnaire}

Questionnaire on: EVALUATING THE NURSING MANAGEMENT OF PATIENTS ON UNDER WATER CHEST DRAINAGE TREATMENT AT KENYATTA NATIONAL HOSPITAL

Serial Number Date of interview

Instructions: Thank you for your willingness to respond to my questions. This session will take 20 - 25 minutes. You will be interviewed as the questionnaire is filled. Your responses will be recorded just the way you put them.

Thank you.

SECTION 1: SOCIAL DEMOGRAPHIC DATA RESPONDENTS AGE

1) How old are you?
a) $21-30$ yrs [ ]
b) $31-40$ yrs [ ]
c) $41-50$ yrs [ ]
d) above 51 yrs [ ]

\section{GENDER}

2) What is your gender?

$\begin{array}{ll}\text { a) Male [ ] } & \text { b) Female [ ] }\end{array}$

\section{LEVEL OF TRAINING}

3) What is your level of completed professional nursing training?

a) Certificate (KECHN) [ ]

b) Diploma (KRCHN) [ ]

c) Bachelors degree $(\mathrm{BScN})[$ ]

d) Masters degree $(\mathrm{MScN})$ [ ]

\section{DEPARTMENT/ DEPLOYMENT}

4) What is your current deployment?

a) Surgery [ ]

b) Medicine [ ]

\section{NURSING EXPERIENCE}

$5)$ What is the length of your experience in nursing practice?
a) 0 - 5 years [ ]
b) 6 - 10 years [ ]
c) 11 - 15 years [ ]
d) 16 - 20 years
[ ] e) Above 20 years [ ]

ATTITUDE

6) What is your perception on the role of nurses in the management of underwater chest drainage?
a) No role [ ]
b) Minimal role [ ]
c) Important role [ ]
d) Very important role [ ]

PARTICIPATION IN CMES

7) Have you ever attended any CME training on the nursing management of underwater chest drainage patient?

a) YES [ ]

b) $\mathrm{NO}[\mathrm{]}$

SECTION 2: NURSES KNOWLEDGE ON UNDERWATER CHEST 


\section{DRAINAGE}

1) What is your level of competence/comfort in the nursing management of a patient on underwater chest drainage?
a) Good [ ]
b) Average [ ]
c) Poor [ ]

2) Rate your knowledge on the nursing assessment of patients on underwater chest drainage?
a) Very good [ ]
b) Good [ ]
c) Average [ ]
d) Poor [ ]

List the components that you know

3) Rate your knowledge on the nursing diagnosis of patients on underwater chest drainage?
a) Very good [ ]
b) Good [ ]
c) Average [ ]
d) Poor [ ]

List the likely components that you know

4) Rate your knowledge on the nursing care planning for patients on underwater chest drainage?
a) Very good [ ]
b) Good [ ]
c) Average [ ]
d) Poor [ ]

List the components that you know

5) Rate your knowledge on the nursing implementation of care for patients on underwater chest drainage?
a) Very good [ ]
b) Good [ ]
c) Average [ ]
d) Poor [ ]

List the components that you know

6) Rate your knowledge on the nursing evaluation and monitoring for patients on underwater chest drainage?
a) Very good [ ]
b) Good [ ]
c) Average [ ]
d) Poor [ ]

List the components that you know

7) Rate your knowledge on the possible complications in patients on underwater chest drainage?
a) Very good [ ]
b) Good [ ]
c) Average [ ]
d) Poor [ ]

List the complications that you know

SECTION 3: ADHERENCE TO THE STANDARD GUIDELINES IN UNDERWATER CHEST DRAINAGE MANAGEMENT

1) Are you aware of any guidelines in underwater chest drainage nursing management?
a) Yes [ ]
b) No [ ]
2) If yes, which guidelines

3) If No, which guidelines do you follow to guide your care provision in underwater chest patients? 
4) Do you adhere to these guidelines during your management of underwater chest drainage patients?

a) Yes [ ]

b) No [ ]

5) If yes, how often do you adhere?
a) Always [ ]
b) Sometimes [ ]
c) Others (Specify)

6) If No, why don't you adhere to the guidelines that you know of?

7) Why do you think nurses do not adhere to standard guidelines?

\section{SECTION 4: CHALLENGES ENCOUNTERED BY THE NURSES WORKING IN KNH ON CHEST DRAIN MANAGEMENT}

1) Do you encounter any challenges during provision of nursing care to underwater chest drainage patients?

a) Yes [ ]

b) No [ ]

2) If yes, which are the challenges that you have come across?

3) Do you regularly give health messages to patients on underwater chest drainage regarding their condition?
a) Yes [ ]
b) No [ ]
4) If no, why?

5) How do you think the nursing management of patients on underwater chest drainage can be improved? 